\title{
A saliva como sendo um meio de diagnósticos: uma revisão de literatura
}

\author{
Saliva as a means of diagnostics: a review of literature
}

Saliva como medio de diagnóstico: una revisa de literatura

José Milton de Aquino e Silva Neto ${ }^{1 *}$, Joana Beatriz Regueira de Souza1, Débora Noêmia da Silva Farias $^{1}$, Andressa Rebecca Coelho Batista ${ }^{1}$, Júllian Karen Bezerra dos Santos ${ }^{1}$, Arlette Murgado

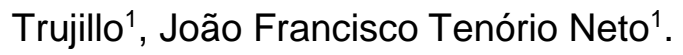

\section{RESUMO}

Objetivo: Realizar uma revisão integrativa de literatura para analisar a complexidade dos biomarcadores constituintes no complexo dos fluidos salivares, demostrando o estado de saúde ou doença de um indivíduo. Métodos: Como estratégia de busca foi estabelecido pesquisas nas bases de dados PubMed/MedLine, LiLacs e SciELo, no período de 2013-2019, combinando os descritores "a importância do fluxo salivar" e "a saliva como meio de diagnóstico e monitorização de eventuais doenças" aos descritores booleanos nas respectivas fontes de pesquisa. Resultados: A aplicação da saliva como forma de diagnósticos além de monitorização de possíveis patologias vem sendo empregado nos últimos anos por causa de sua forma simplória, económica e não invasiva. Estas particularidades fazem com quer ela seja um caminho benéfico quando é comparada ao recolhimento de sangue e urina, facilitando a detecção antecipada de determinadas doenças em estágio inicial, por conta da presença de biomarcadores salivares específicos. Considerações Finais: A saliva é um fluido biológico encontrado na cavidade oral que possui bastante relevância na correlação fisiológica quanto patológica constituinte do ser humano. O benefício da sua aplicação como em exames laboratoriais estabelece pelo fato de sua disposição, forma menos invasiva, de fácil recolhimento, baixo custo sendo comparados com outras formas de diagnósticos.

Palavras-chave: Salivação, Glândulas salivares, Medicina bucal, Manifestações bucais.

\section{ABSTRACT}

Objective: Perform an integrative literature review to analyze the complexity of the constituent biomarkers in the salivary fluid complex, demonstrating the health or disease status of an individual. Methods: As search strategy, searches were established in the PubMed/ MedLine, LiLacs and SciELo databases, in the period 2013-2019, combining the descriptors "the importance of salivary flow" and "saliva as a means of diagnosis and monitoring of eventual diseases". Boolean descriptors in their respective research sources. Results: The application of saliva as a form of diagnosis in addition to monitoring possible pathologies has been employed in recent years because of its simple, economic and noninvasive form. These features make it a beneficial path when compared to blood and urine collection, facilitating early detection of certain early-stage diseases due to the presence of specific salivary biomarkers. Final Considerations: Saliva is a biological fluid found in the oral cavity that is very relevant in the physiological and pathological correlation that constitutes the human being. The benefit of its application as in laboratory tests establishes by the fact that its availability, less invasive, easy to collect, low cost being compared with other forms of diagnosis.

Key Words: Salivation, Salivary glands, Oral medicine, Oral manifestations.

${ }^{1}$ Centro Universitário CESMAC (CESMAC), Maceió - Alagoas. *E-mail: milton_neto_166@hotmail.com 


\section{RESUMEN}

Objetivo: Realice una revisión de la literatura integradora para analizar la complejidad de los biomarcadores constituyentes en el complejo de fluido salival, demostrando el estado de salud o enfermedad de un individuo. Métodos: Como estrategia de búsqueda, las búsquedas se establecieron en las bases de datos PubMed/ MedLine, LiLacs y SciELo, en el período 2013-2019, combinando los descriptores "la importancia del flujo salival" y " la saliva como médio de diagnóstico y monitoreo de enfermedades eventuales". Descriptores booleanos em sus respectivas fuentes de investigación. Resultados: La aplicación de la saliva como forma de diagnóstico además de monitorear posibles patologias se ha empleado en los últimos años debido a su forma simple, económica y no invasiva. Estas características lo convierten en un camino beneficioso en comparacción con la recolección de sangre y orina, lo que facilita la detección temprana de ciertas enfermedades en etapa temprana debido a la presencia de biomarcadores salivales específicos. Consideraciones finales: La saliva es un fluido biológico que se encuentra en la cavidad oral y que es muy relevante en la correlación fisiológica y patológica que constituye el ser humano. El beneficio de su aplicación como en las pruebas de laboratorio se establece por el hecho de que su disponibilidad, menos invasiva, fácil de recolectar, de bajo costo en comparación con otras formas de diagnóstico.

Palabras clave: Salivación, Glándulas salivales, Medicina oral, Manifestaciones bucales.

\section{INTRODUÇÃO}

Para o bom funcionamento do organismo humano é necessário que ele possua uma condição adequada de água no seu interior, com a diminuição no corpo humano ocorre a redução significativa do fluxo salivar presente na cavidade oral. A saliva é de suma importância para a saúde bucal, além de desempenhar um fundamental papel no processo da ingestão do bolo alimentar e o correto desempenho na regulamentação dos organismos, sendo conceituada por muitos cientistas como um espelho do corpo, observado que possui a habilidade de demonstrar com bastante clareza como o corpo encontra-se, estando ele saudável ou não, concedendo a constatação, supervisão e terapêuticas satisfatórias de inúmeras enfermidades (BELSTRØM D, et al., 2017). A grande concentração de moléculas que estão compostas no plexo salivar é responsável pelas demarcações biológicas, tornando-as indispensáveis no reconhecimento de estipulados níveis de doença nos pacientes (CROSS BW e RUHL S, 2018).

O fluido mais utilizado no corpo dos seres humanos é o sangue, ele é utilizado para diagnosticar a forma que nosso corpo se encontra, muitos estudos relatam que o sangue possui relação direta com a saliva, esse fato se dá devido a existência de ligações celulares e moleculares entre esses fluidos. A correlação estabelecida entre esses dois fluidos existentes no corpo explica-se devido ao fato dos processos mecânicos de difusões passivas e dos transportes recorrentes ativos que se restabelece pela ultrafiltração das membranas, pelo meio das habilidades dos fluidos da cavidade bucal obter moléculas transladados pelo sistema circulatório - sangue (CROSS BW e RUHL S, 2018).

O acúmulo do fluxo salivar das moléculas e a suas prováveis modificações simplificam o reconhecimento tanto do estado fisiológico normal, como de possíveis enfermidades ou até mesmo decifrações do corpo a estipulados recursos terapêuticos. De acordo com a averiguação da existência de diversos constituintes parecidos entre a saliva e o sangue, tais como: Ácido Desoxirribonucleico, ácido ribonucleico, ligações peptídicas, aminoácidos, lipídios, grande concentração de anticorpos, entre outros, da mesma forma é plausível propor e averiguar a possibilidade do estudo salivar como sendo um competente recurso de identificação optativo à verificação sanguínea (HAMOUDI ALN, et al., 2018).

Os estudos científicos relacionados com a saliva possuem como foco principal a detecção e reconhecimento de eventuais patologias preexistentes ou existentes, bem como o acompanhamento terapêutico (PEZELJ-RIBARIC S, et al., 2015). A relevância de analisar o fluxo salivar, surgiu em 1975 com Dawes, onde o mesmo queria analisar a saúde do indivíduo através da prevalência do fluxo salivar, em seus estudos obteve uma resposta significativa com resultados positivos e Dawes ressaltou que essa técnica seria 
muito útil para a sociedade visto que precisaria de baixo custo para a obtenção de determinados diagnósticos por conta da extrema facilidade do colhimento da amostra, além da perspectiva da obtenção mais detalhada de inúmeras informações dos componentes integrantes correntes nesse fluxo orgânico e inorgânico (RATHNAYAKE N, et al., 2016).

Com isso, o emprego da saliva como fonte de variados diagnósticos vem sendo empregados em clínicas e laboratórios, uma vez que consente resultados satisfatórios e precisos além de ser uma forma bastante rápida e não invasiva para a obtenção do seu resultado. (EBERSOLE JL, et al., 2015). Vários órgãos governamentais e não governamentais cada vez mais têm apoiado esses estudos, visto que algumas das empresas relacionadas com a implantação dessa nova técnica ajuda de forma financeira e busca sempre utilizar tecnologia de ponta para obtenção de melhores resultados, diminuindo dessa forma os obstáculos que foram encontrados logo no começo da pesquisa. Algumas empresas se destacam no âmbito mundial devido ao financiamento que se disponibilizam em fazer para esse projeto ganhar mais credibilidade, entre elas estão: National Institute of Dental and Craniofacial Research (NIDCR), American Association of Dental Research, National Institutes of Health (NIH), American Dental Association (ADA), e Fédération Dentaire Internationale (FDI, World Dental Federation) (SLOWEY PD, 2015).

Os primeiros estudos feitos com o fluxo salivar eram restritos apenas a cavidade oral, buscava-se sempre analisar sua concentração, forma que apresentava-se através de anamneses feitas nas primeiras consultas odontológicas, no entanto nas últimas décadas foram observados as suas importâncias para detecção de doenças não só orais como também sistêmicas, isso se deu através de estudos microscópicos mais aprofundados, sendo estudado todas as particularidades que apresenta-se com suas composições (FUNAHARA M, et al., 2018).

As pesquisas cientificas propiciaram analisar a correlação da saliva e o alto risco de carie, problemas relacionados com as glândulas salivares relacionados a infecções virais agudas e congênitas, candidose mediante a assiduidade de Candida spp na saliva, como também de doenças periodontais, no entendo não se restringi apenas a esses diagnósticos, como também inúmeras doenças sistêmicas, dos quais se destacase espécimes clinicas como a rubéola, controle de virose em determinada população, biópsias gástricas se empregando a hidrólise da uréase para análise de Helicobacter pylori o diagnóstico do Vírus da Imunodeficiência Humana (HIV), além do teste de DNA (BURLEIGH MC, et al., 2018).

Com isso, esse estudo possuiu como objetivo analisar as formas de se estabelecer o fluxo salivar como uma possível forma de obter diagnósticos precisos tanto em doenças orais como em doenças sistêmicas principalmente as que são mais relacionadas aos processos cariosos e periodontais, mencionando os biomarcadores presentes na saliva.

\section{METODOLOGIA}

Esta pesquisa constituiu-se através de uma revisão integrativa de literatura descritiva realizada entre os períodos de junho de 2019 a novembro de 2019, onde foram analisados artigos publicados em bases de dados eletrônicos, Literatura Latino Americana e do Caribe em Ciências da Saúde (LILACS), Literatura Internacional em Ciência da Saúde (MEDLINE) e Scientific Electronic Library Online (SCIELO) e livros que estavam disponíveis nos acervos bibliográficos presentes na biblioteca central do Centro Universitário CESMAC (Centro de Ensino Superior de Maceió).

Para tanto o estudo foi estabelecido através dos seguintes critérios: Os desenhos dos estudos deveriam ser ensaios clínicos controlados randomizados em humanos, no idioma inglês, espanhol e português, escolhidos os trabalhos publicados nos últimos 5 anos (2015 a 2019). Conforme a metodologia descrita por Costa EK, et al., (2019), os artigos foram estabelecidos por 5 pesquisadores: a princípio foi estabelecida e analisada a temática e subsequentemente, a leitura minuciosa dos respectivos resumos para a utilização da circunspecção restringindo-os. Logo após foram asseguradas as leituras de todos eles, tal qual se aproveitou os subsídios de proveito, como também foram apuradas as listas de referências, com o objetivo de localizar artigos que incrementassem para o enriquecimento da respectiva revisão integrativa. 
Com os artigos designados, foram organizados os itens das centrais variáveis de instância, como a grandeza da amostra, o objetivo, a metodologia, os parâmetros analisados e os fundamentais resultados, que se referiram a utilização da saliva como meio de diagnóstico, tendo como critérios de exclusão os períodos de publicações, relatos de casos, séries de casos, ensaios não controlados, monografias e os artigos que não possuíam relevância com a temática, sendo selecionados os textos científicos que apresentavam na íntegra o real objetivo do trabalho, que era observar e analisar estudos na literatura científica envolvendo a saliva como diagnóstico de doenças bucais e sistêmicas. Os descritores utilizados foram: Diagnóstico Salivar, mediadores salivares, técnicas e procedimentos de laboratório.

\section{RESULTADOS E DISCUSSÃO}

Para o decorrer introdutório da respectiva revisão, foi determinado 26 artigos que estavam apresentavamse completude nas respectivas bases de dados. Na evolução que foi obtido, 10 apresentavam-se com duplicidade nas referidas fontes de estudos, mantendo-se 16 artigos para a avaliação do conteúdo, no entanto quatro foram descartados por não possuírem de forma adequada as diretrizes principais da construção do estudo. Consequentemente 12 artigos introduziram-se para a definição e avaliação mediante das sínteses existentes, quatro foram exclusos, desta maneira, ficaram estabelecidos 8 para a elucidação e constituição primordial para o desenvolvimento do estudo. Depois de serem feitas as observações do estudo determinadas destes, ausentou-se outra fonte de pesquisa. No fim dos levantamentos informativos, a revisão foi composta por 8 artigos científicos de grande relevância, e o fluxograma da (Figura 1) menciona todas as formas de investigação produzidas mediante de apuramento feito por pesquisas decididas para a elucidação direta desta análise literária.

Figura 1 - Fluxograma dos estudos identificados.

Números de registros que estavam catalogados nas bases de dados: 26
Números de registros adicionais, catalogados em outras bases de dados: $n=0$

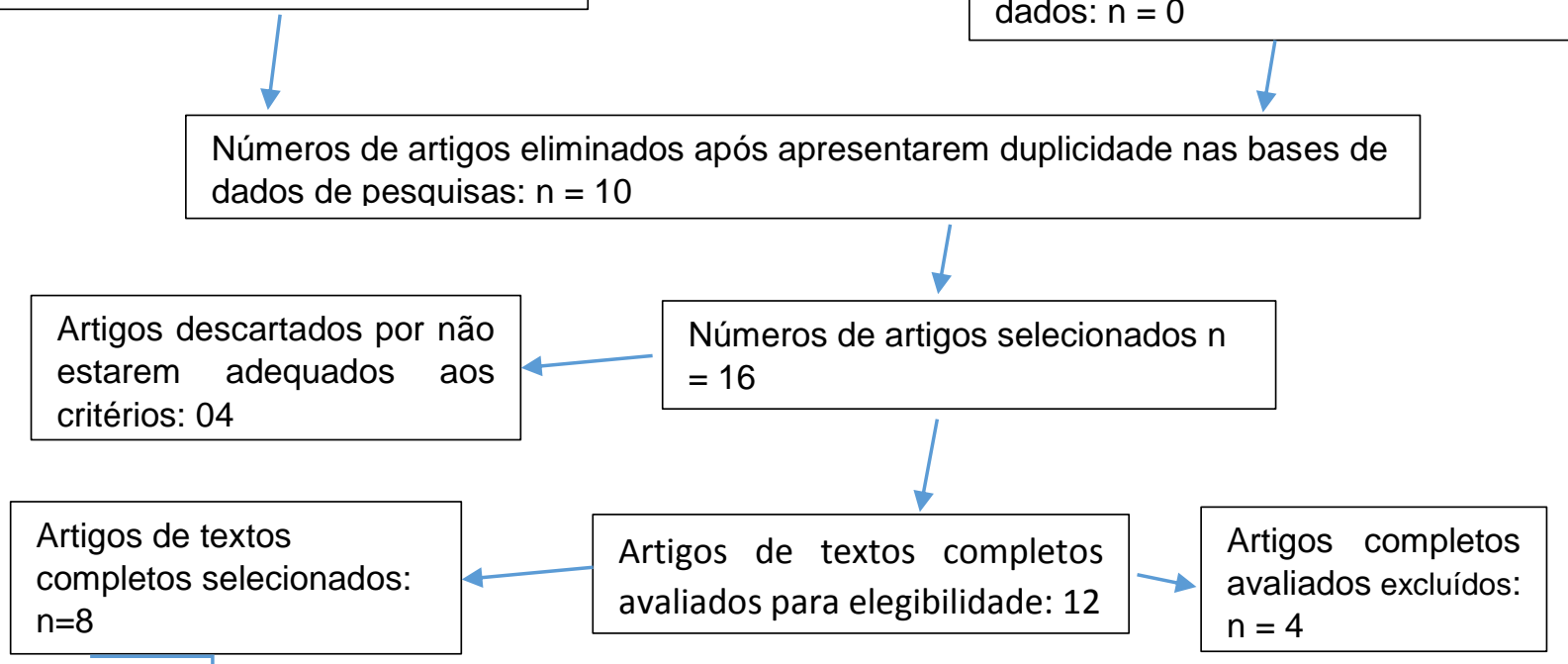

completos selecionados:
BHATTARAI KR, KIM HR, CHAE HJ (2018).

NUNES LA, MUSSAVIRA S, BINDHU OS (2015).

MACIEL SS, FERES M, GONÇALVES TE, et al. (2016).

RATHNAYAKE N, HEIKKINEN AM, NWHATOR SO, et al (2016).

BURLEIGH MC, LIDDLE L, MONAGHAN C, et al. (2018).

CROSS BW, RUHL S (2018).

KOCHUROVA EV, KOZLOV SV (2014).

WANG Y (2017).

Fonte: Neto JMAS, et al., 2019. 
Os artigos possuíram suas informações através dos tópicos: autor/ano, país, objetivo e resultados, os quais foram tabulados e apresentados abaixo (Quadro 1).

Quadro 1 - Delineamento, métodos e principais desfechos dos estudos selecionados.

\begin{tabular}{|c|c|c|c|c|}
\hline Autor & Ano & País & Objetivo & Resultados \\
\hline $\begin{array}{l}\text { BHATTARAI } \\
\text { KR, KIM HR, } \\
\text { CHAE HJ }\end{array}$ & 2018 & $\begin{array}{l}\text { República } \\
\text { da Coréia }\end{array}$ & $\begin{array}{l}\text { Utilizar a saliva como técnica através da } \\
\text { biociência salivar, como eletroforese, sendo } \\
\text { aplicadas para diagnosticar o estado de } \\
\text { saúde sistêmico dos pacientes. }\end{array}$ & $\begin{array}{l}\text { Os diagnósticos salivares foram até identificados como potenciais } \\
\text { substitutos dos biomarcadores de proteínas séricas. No entanto, o protocolo } \\
\text { ideal para a coleta de saliva ainda não foi padronizado. }\end{array}$ \\
\hline
\end{tabular}

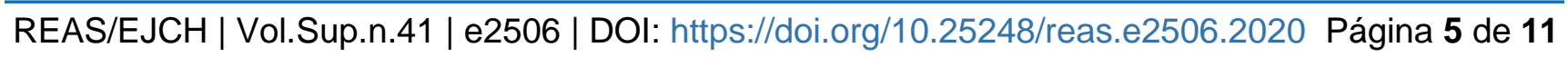




\begin{tabular}{|c|c|c|c|c|}
\hline $\begin{array}{l}\text { RATHNAYAKE } \\
\text { N, HEIKKINEN } \\
\text { AM, } \\
\text { NWHATOR } \\
\text { SO, et al. }\end{array}$ & 2016 & Finlândia & $\begin{array}{l}\text { Investigar um teste de enxágue bucal no } \\
\text { local da cadeira (Periosafe), com base no } \\
\text { imunoensaio de MMP-8, para identificar } \\
\text { pacientes com carga inflamatória oral } \\
\text { (periodontite e cárie) em adolescentes com } \\
\text { achados patológicos precoces. }\end{array}$ & $\begin{array}{l}\text { A sensibilidade e especificidade do imunoensaio de neutrófilos colagenase- } \\
2 \text { para os positivos da BOP foi de } 71,8 \% \text { e a especificidade de } 77,5 \% \text { ( } p= \\
0,018 \text { ), para pelo menos uma bolsa de profundidade } \geq 4 \mathrm{~mm} 48.3 \% \text { e } 100 \% \\
(0<0,0001 \text { ), pelo menos dois bolsos } \geq 4 \mathrm{~mm} \text { de profundidade } 63,6 \% \text { e } 100 \% \\
(p<0,0001 \text { ), mais de dois bolsos } \geq 4 \mathrm{~mm} \text { de profundidade } 76,5 \% \text { e } 96,8 \% \text { ( } p \\
<0,0001 \text { ), respectivamente. Em relação à periodontite (pelo menos uma } \\
\text { bolsa } \geq 4 \mathrm{~mm} \text { de profundidade), quase nenhum falso positivo pode ser } \\
\text { identificado. A sensibilidade do imunoensaio de neutrófilos colagenase-2 } \\
\text { para pelo menos uma lesão de cárie foi de } 76,5 \% \text { e a especificidade de } \\
96,7 \% \text { ( } p<0,01 \text { ). Conclusão: O teste lateral da cadeira PerioSafe aMMP-8 } \\
\text { analisando enxaguatório bucal a MMP-8 mostrou resultados promissores no } \\
\text { reconhecimento da carga inflamatória oral em adolescentes com sinais } \\
\text { iniciais precoces de periodontite em } 5 \text { minutos. }\end{array}$ \\
\hline $\begin{array}{l}\text { BURLEIGH } \\
\text { MC, LIDDLE L, } \\
\text { MONAGHAN } \\
\text { C, et al. }\end{array}$ & 2018 & Escócia & $\begin{array}{l}\text { O óxido nítrico (NO) pode ser gerado } \\
\text { endogenamente via sintase de NO ou via } \\
\text { dieta após a ação de bactérias redutoras de } \\
\text { nitrato simbiótico na cavidade oral. Dado o } \\
\text { importante papel do NO no controle da } \\
\text { musculatura lisa, há uma sugestão intrigante } \\
\text { de que a homeostase cardiovascular possa } \\
\text { estar entrelaçada com a presença dessas } \\
\text { bactérias. }\end{array}$ & $\begin{array}{l}\text { A produção de nitrito salivar foi menor nos participantes com menor } \\
\text { abundância de bactérias e esses indivíduos também exibiram } \\
\text { farmacocinética mais lenta do nitrito salivar. Portanto, mostramos que a taxa } \\
\text { de redução de nitrato para nitrito na cavidade oral está associada à } \\
\text { abundância de bactérias redutoras de nitrato. }\end{array}$ \\
\hline $\begin{array}{l}\text { CROSS BW, } \\
\text { RUHLS }\end{array}$ & 2018 & $\begin{array}{l}\text { Estados } \\
\text { Unidos } \\
\text { da } \\
\text { America. }\end{array}$ & $\begin{array}{l}\text { Delinear como os mecanismos de defesa do } \\
\text { hospedeiro mediados por glicanos na } \\
\text { cavidade oral apoiam a saúde } \\
\text { humana. Descreveremos o papel dos } \\
\text { glicanos ligados às glicoproteínas salivares } \\
\text { de tamanho molecular grande que atuam } \\
\text { como uma primeira linha de defesa do } \\
\text { hospedeiro primordial na boca humana. }\end{array}$ & $\begin{array}{l}\text { Os componentes proteicos e glicoproteicos da saliva desempenham um } \\
\text { papel particularmente importante na modulação da microbiota oral e na } \\
\text { liberação de patógenos. Há muito tempo se reconhece que os aspectos } \\
\text { glicobiológicos e glicoimunológicos desempenham um papel central nas } \\
\text { interações orais hospedeiro-micróbio, micróbio-hospedeiro e micróbio- } \\
\text { micróbio na boca. }\end{array}$ \\
\hline
\end{tabular}

REAS/EJCH | Vol.Sup.n.41 | e2506 | DOI: https://doi.org/10.25248/reas.e2506.2020 Página $\mathbf{6}$ de 11 
Revista Eletrônica Acervo Saúde / Electronic Journal Collection Health ｜ ISSN 2178-2091

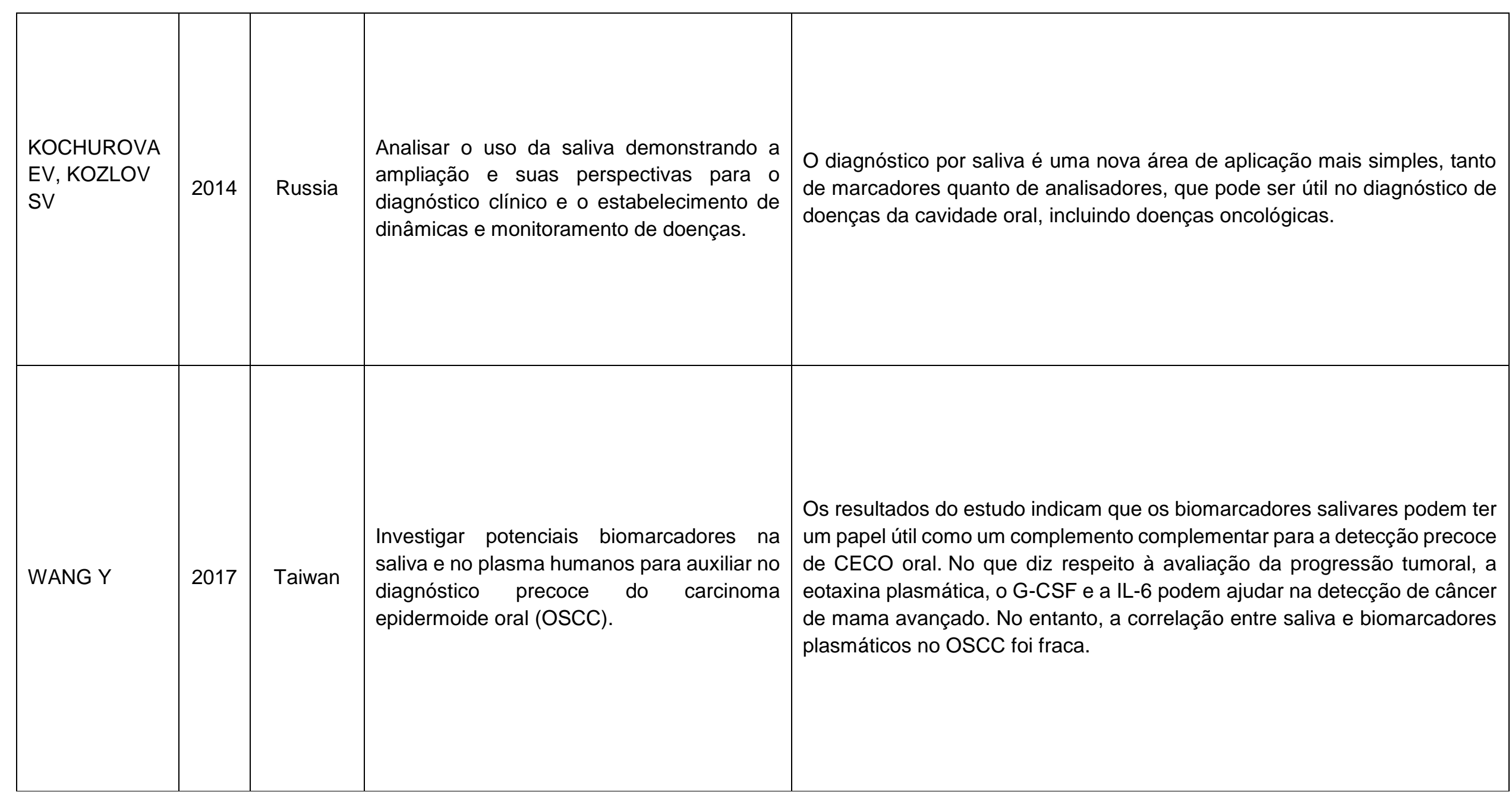

Fonte: Neto JMAS, et al., 2019. 
A saliva apresenta uma secreção aquosa sendo um constituinte fundamental na vida dos seres humanos encontrada no biofluido oral, seu potencial hidrogeniônico $(\mathrm{pH})$ normal é estabelecido entre 6,5 e 7, formada na grande maioria das vezes por água (98\%) e por eletrolíticos como: Sódio $(\mathrm{Na}+)$, Potássio $(\mathrm{K}+)$, Cálcio (Ca2+), Magnésio (Mg2+), Cloreto ( $\mathrm{Cl}-$ ), Fosfato do hidrogênio (HPO42-), Carbonato de hidrogênio (HCO3-), muco, compostos que regularizam as funções antibacterianas e inúmeras enzimas (BHATTARAI KR, et al., 2018). O fluxo salivar é produzido respectivamente em três grandes grupos de glândulas salivares sendo elas as parótidas, submandibulares e sublinguais encontradas na boca e garganta, existindo também as glândulas salivares menores que dispõem de uma pequena contribuição, onde são repartidas por toda a cavidade bucal e pelos fluidos creviculares gengivais (FCG), juntas formam a saliva total (NUNES LAS, et al., 2015). Devido seu grau de complexidade elevado, devido a presença de compostos corporais de segmentação multifatorial entre eles pode-se destacar a integridade da cavidade oral e do sistema digestivo, consequentemente é uma fonte fundamental de proteção contra infecções nesses órgãos presentes (MACIEL SS, et al., 2016).

Alguns corpúsculos da constituição salivar possuem propriedades de serem marcadores biológicos associados com inúmeras patologias sistematizadas quanto orais, possibilitando por sua vez o reconhecimento e monitoramento uniformemente das mesmas. As individualidades representadas em relação aos seus componentes integrantes (RATHNAYAKE N, et al., 2016). A saliva possui um papel bastante relevante no que se refere a diagnósticos e prognósticos visto que sua composição é composta de $98 \%$ de água e $2 \%$ de componentes orgânicos e inorgânicos, apresentando um PH que varia entre 6,5 a 7, geralmente a média de produção salivar de um indivíduo sadio é de 0,5 à $1,51 /$ dia, onde suas glândulas salivares maiores apresentam 90\% da secreção, e as menores 10\% (RATHNAYAKE N, et al., 2016).

Além de possuir outras propriedades como a monitorização de doenças bucais e sistêmicas, avaliações de tratamentos feitos mediante do estudo do fluxo salivar, ela possui defesa antibacteriana, serve como processo digestivo através dos seus bolos alimentares produzidos, atua como melhora na lubrificação alimentar e processos mastigatórios, lavagens, solubilidades e a capacidade tampão onde mantem a integridade dos dentes e da mucosa bucal. Sendo crucial como biomarcadores correlacionados com agentes patogénicos responsáveis pela doença periodontal e cárie (RATHNAYAKE N, et al., 2016).

Geralmente o colhimento salivar pode ser feito através de dois processos, a forma mais convencional que é sem estimulação ou com bioestimuladores salivares, para poder saber qual técnica utilizar é necessário observar a quantidade de saliva que é produzida na cavidade bucal, geralmente a média varia entre 0,1$0,3 \mathrm{ml} / \mathrm{min}$, se por acaso o paciente não tiver essa quantidade são feitas estimulações para a produção salivar com pastilha almofadadas, parafinas ou por utilização de ácido cítrico próximo das papilas lingual, existem inúmeras formas do colhimento salivas entre elas destacam-se: As obtidas por tubetes de plástico predominantemente pelo "passive drooling", conseguindo além do mais pela atividade de cuspir, por rolo de algodões ou até mesmo aspiração e seguidamente essas amostras são centrifugadas para a obtenção da amostragem (BURLEIGH MC, et al., 2018).

Esses métodos utilizados são bastantes significativos, porém o operador deve obter cuidado para não alterar e modificar as substâncias presentes (CROSS BW e RUHL S, 2018). Existe a possibilidade da obtenção da saliva específica em cada glândula, esse procedimento é feito através da retirada da saliva diretamente do ducto glandular que se deseja. Geralmente essa forma de obtenção é realizada quando o paciente possui uma possível infecção específica ou até mesmo uma provável obstrução recorrente na mesma correlacionada a patologias ou não.

No entanto, o equipamento utilizado para o colhimento dessa forma tão especifica é demorado e invasivo quando se comparado aos métodos convencionais, exigindo do profissional responsável bastante habilidade e conhecimento especifico de cada glândula presente na cavidade oral, existem vantagens e desvantagens no processo de diagnostico salivar (MITSUI T e HARASAWA R, 2017).

\section{Vantagens}

A saliva possui inúmeros constituintes capazes de analisar o estado real de saúde do paciente, sedo cada vez mais utilizada devido sua forma simplória e bastante rápida além de não ser invasiva, podendo ser obtido 
inúmeras amostragens no mesmo atendimento. O profissional não precisa de muita técnica quando é obtido o colhimento das formas convencionais e não especificas, ao contrário das técnicas que utilizam a obtenção do sangue possui baixo custo no colhimento, armazenamento, na locomoção, o que se torna bastante eficaz quando é feito diagnostico em grande escala de determinada população, beneficiando tanto a população quanto o órgão responsável pela análise das amostragens (MITSUI T e HARASAWA R, 2017).

Quando é correlacionada a porcentagem de contaminação cruzada, esse método é o mais eficaz quando se compara com o exame de sangue e urina além de que a capacidade de contrair HIV por eventuais decorrências é bastante reduzida devido fatores existentes nas secreções salivares e é um método eficaz para pacientes que possuam algumas particularidades como coordenação motora, pacientes especiais, idosos, pacientes ansiosos, crianças (BURLEIGH MC, et al., 2018).

\section{Desvantagens}

Observa-se que há uma falta de um protocolo padronizado para a detecção e resultado, possuindo limitações em glândulas salivares especificas devido subsistência e condições que modifiquem suas composições, a abundância pode modificar a composição secretada da saliva, comprometendo os prognósticos e diagnósticos, quando é feito o processo de utilização da técnica da bioestimulação, acarreta o aumento salivar, porém a sua concentração torna-se mais diluída, diminuindo a concentração de biomarcadores, o que pode prejudicar a detecção correta (WANG Y, 2017).

No processo de armazenamento e transporte das amostras, deve-se ter cuidado com contaminação por bactérias, então o profissional deve ter cuidado para que não alterações significativas, em caso de armazenamento a longo prazo ela deve ser colocada em uma temperatura de $-20^{\circ} \mathrm{C}$ à $-80^{\circ} \mathrm{C}$. Dependendo da técnica utilizada e como será feito o diagnostico não passar de duas semanas guardadas, isso porque a $\alpha$-amilase e alguns antioxidantes com peso molecular pequeno diminui, ter atenção na concentração de cortisol, devido as alterações com temperatura ambiente (CROSS BW e RUHL S, 2018).

\section{Amostragens}

O recolhimento do fluxo salivar deve ser feito com o paciente em jejum, isso se deve ao fato de alguns alimentos alterarem a quantidade expelida pelas glândulas. Em foco, a ingestão tanto de bebidas alcoólicas ou não e os alimentos principalmente ácidos, podem diminuir o nível do $\mathrm{pH}$ da cavidade bucal, aumentando as chances das amostragens possuírem um alto nível de contaminação bacteriana, se o paciente não estiver em jejum é necessário pedir para o mesmo fazer uma limpeza na cavidade oral com água destilada e esperar um período de 30 minutos para obter um nivelamento do $\mathrm{pH}$ o mais habitual possível (NUNES LAS, et al., 2015).

\section{Diagnósticos}

Para a obtenção de um diagnóstico correto é importante avaliar os biomarcadores específicos, estando eles de formas particularizadas ou em conjunto, quando esses biomarcadores são utilizados de forma conjuntas para a análise de uma ou mais doenças titula-se por "assinatura molecular". É imprescindível que a execução do reconhecimento dos marcadores biológicos salivares relacionados a determinada patologia possua uma forma criteriosa, ou seja, precisa ser apresentada uma triagem apropriada dos enfermos a englobar nos estudos, um recolhimento invariável das amostragens e diversos ensaios laboratoriais.

A metodologia se dá início a partir da distinção de uma circunstância ambulatorial em que a saliva consegue revelar-se adequada, certificando-se a inflexibilidade da regulamentação do estudo para só assim poder fazer a aplicação clínica (WANG Y, 2017).

Um dos modelos mais utilizados atualmente na obtenção do diagnostico salivar é o de PROBE (prospective randomized open blinded end-point) esse método se fundamenta em normas particulares, buscando adquirir uma análise não tendenciosa, onde torna maior a hipótese de êxito do emprego de marcadores biológicos (KOCHUROVA EV e KOZLOV SV, 2014). Imediato ao processo de distinção de uma circunstância laboratorial, encaminha-se a etapa de apuramento salivar. Oposto do colhimento sanguíneo, o recolhimento dos fluidos salivares consegue ser melhor e eficaz pelo fato do motivo de não precisar de punções venosas, 
procedimentos anticoagulantes com objetivos de supressão dos glóbulos vermelhos presentes, o que influencia de forma proveitosa a expectativa de êxito do trabalho realizado (WANG Y, 2017).

Por último, as manipulações das amostragens obtidas para investigação no laboratório são registradas as propriedades do fluxo salivar colhido para que ocorra o processo de adequação nos estudos de averiguação e comprobação a ser realizada. Para esse fim, é essencial que haja a subsistência de etapas no processo de controles de qualidade, de especificação e aprovisionamento, assim como as documentações de todas as fases executadas na realização do trabalho feito (BURLEIGH MC, et al., 2018).

Ao se comparar a validação das relações dos marcadores biológicos presentes na saliva e estipuladas enfermidades patológicas, são prováveis as detecções precocemente delas. Um dos seus melhores benefícios é esse, pois através desse fator pode-se minimizar a gravidade da doença existente logo no seu início, prevenindo assim eventuais agravos que sejam capazes de baixar de modo considerável o bem-estar do paciente, colaborando com a taxa de vitória no que se refere ao tratamento (JAVAID MA, et al., 2016). Quando se refere a doenças que possuem relevância mundial, como acontece com as doenças do cancro oral, é observado que os biomarcadores da cavidade oral, mas especificamente os salivares, estabelecem maiores efeitos benéficos na detecção prematura dessa enfermidade, quando se comparada a diagnósticos feitos por biomarcadores plasmáticos (CSOSZ E, et al., 2017).

O diagnóstico o mais cedo possível sendo feito torna-se melhor os resultados positivos e possibilita um tratamento mais eficaz, visto que várias doenças são silenciosas e os pacientes na maioria das vezes só sabem o que tem, quando desenvolvem determinadas sintomatologias, mais especificamente na etapa mais mórbida como acontece em pacientes com carcinomas glandulares e portadores de HIV (RATHNAYAKE N, et al., 2016). Mesmo a maioria da população sabendo que é necessário fazer os exames periódicos com frequência, até mesmo os que possuem ou desconfiam de alguma enfermidade, constantemente objetam a fazer. Isto ocorre, na maioria dos casos, ao medo de submeterem-se a exames que possuem uma forma mais agressiva no sentido de ser invasivo e bastante desconfortante para muitos. Devido esse motivo existe a procura por métodos que não sejam invasivos, habilidosos e confiáveis com o propósito de contornear estes empecilhos, proporcionando uma interferência logo no estágio inicial e precavendo possíveis impasse ou até mesmo sequelas (RATHNAYAKE N, et al., 2016).

A análise feita através dos biomarcadores moleculares, busca como foco central a integridade dos fluidos presentes na saliva, sendo abrangido em diferentes áreas profissionais da saúde, sendo elas: Na enfermagem através do acompanhamento dos fluxos salivares e os medicamentos utilizados pelos pacientes, a área da medicina especifica na área, os multiprofissionais que possuem especializações em técnicas forenses e a detecção de drogas ilícitas e assim por diante. Salienta-se inclusive atualmente a sua relevância nos processos de diagnósticos de inúmeras patologias bucais e problemas sistémicos (BURLEIGH MC, et al., 2018).

De modo relativo às doenças que prejudica o meio bucal como um todo são ocasionadas devido a problemas relacionados a carcinomas, cancro duro, periodontites, gengivites, processos cariosos, candidíase, e essas patologias vem aumentando gradativamente, com isso torna-se indispensável o seu diagnóstico precoce. Para tal fim, é fundamental que os recursos feitos na elaboração do diagnóstico final na cavidade oral estejam eficientes ao ponto de constatar o real nível patológico que se encontra a doença, dando a devida concordância de buscar estabelecer uma conjectura individualizada no prognostico, identificando no que the concerne o ponto principal da patologia e seu estágio (SLOWEY PD, 2015). Os relevantes empasses observados no diagnostico salivar encontra-se na ausência de estabelecimento de um padrão no que se refere a metodologias feitas padronizadas por todos os profissionais no ato da recolha salivar, na manipulação e investigação salivar, a alterabilidade de acúmulo de potencialidade dos marcadores moleculares nos elementos dentários com e sem cancro duro. A solução destas problematizações conseguirá transformar o diagnóstico final mais fiel (CROSS BW e RUHL S, 2018). Os pesquisadores ressaltam a despeito da transcendência dos ajustes de biomarcadores que, correlacionada à uniformização dos recursos terapêuticos da demonstração do fluxo salivar, será capaz de proporcionar seguimentos competentes na detecção adiantada do diagnóstico correto (SLOWEY PD, 2015), (WANG Y, 2017). 


\section{CONSIDERAÇÕES FINAIS}

Ao ser feito uma aprofundada revisão de literatura dos artigos científicos com o objetivo de obter qualidade científica do respectivo assunto, observou-se que a saliva é um fluido biológico encontrado abundantemente na cavidade oral, possuindo bastante relevância na correlação fisiológica quanto patológica constituinte do ser humano. O benefício da sua aplicação como em exames laboratoriais estabelece pelo fato de sua disposição, forma menos invasiva, de fácil recolhimento, no entanto são necessários mais estudos aprofundados para torna essa técnica mais presente na população, visto que beneficia de forma significativa tanto a população quanto o sistema de saúde que irá fazer essas coletas devido a forma simplória de fazer o diagnóstico, como também a redução de tempo e custo para ambos.

\section{REFERÊNCIAS}

1. BELSTRØM D, et al. Salivary microbiota in individuals with different levels of caries experience. Journal of Oral Microbiology, v.9, 2017; p. 1-8.

2. BHATTARAI KR, et al. Compliance with Saliva Collection Protocol in Healthy Volunteers: Strategies for Managing Risk and Errors. International Journal of Medical Sciences. 2018; 15 (8): 823-831.

3. BURLEIGH MC, et al. Salivary nitrite production is elevated in individuals with a higher abundance of oral nitratereducing bacteria. Free Radical Biology and Medicine, 2018; 120 (1): 80-88.

4. COSTA EK, et al. Análise do efeito da radiofrequência no tratamento de flacidez cutânea relacionada ao processo de envelhecimento: revisão integrativa. Revista Eletrônica Acervo Saúde, 2019; Vol.Sup.31: p.3-4.

5. CROSS BW, RUHL S. Glycan recognition at the saliva - Oral microbiome interface. Cellular Immunology. 2018; p.115.

6. CSOSZ E, et al. Proteomics investigation of OSCC-specific salivary biomarkers in a Hungarian population highlights the importance of identification of population-tailored biomarkers. PLoS ONE, 2017; 12(5), 1-21.

7. EBERSOLE JL, et al. Targeted salivary biomarkers for discrimination of periodontal health and disease(s). Frontiers in Cellular and Infection Microbiology, 5(August), 2015; p. 1-12.

8. FUNAHARA M, et al. An analysis of the factors affecting the number of bacteria in the saliva of elderly adults in need or care. International Journal of Gerontology 2018; 12 (1): p. 205-207.

9. HAMOUDI ALN, et al. Non-surgical periodontal therapy reduces salivary adipocytokines in chronic periodontitis patients with and without obesity. Journal of Investigative and Clinical Dentistry 2018; p. 1-7.

10. JAVAID MA, et al. Saliva as a diagnostic tool for oral and systemic diseases. Journal of Oral Biology and Craniofacial Research. 2016; 6(1), 67-76.

11. KOCHUROVA EV, KOZLOV SV. The diagnostic possibilities of saliva. Clinical Laboratory Diagnostics $2014 ; 1$ (1): 13-5.

12. MACIEL SS, et al. Does obesity influence the subgingivalmicrobiota composition in periodontal health and disease? Journal of Clinical Periodontology 2016; 43: 1003-1012.

13. MITSUI T, HARASAWA R. The effects of essential oil, providone-iodine, chlorhexidine mouthwash on salivary nitrate/nitrite and nitratereduncing bacteria. Journal of oral Science 2017; 1 (1): 1-5.

14. NUNES LAS, et al. Clinical and diagnostic utility of saliva as a non-invasive diagnostic fluid: A systematic review. Biochemia Medica, 2015; 25(2), 177-192.

15. PEZELJ-RIBARIC S, et al. Saliva as a diagnostic fluid. Sanamed, 10(3) 2015; p. 215-220.

16. RATHNAYAKE N, et al. Pilot Study on Oral Health Status as Assessed by an Active Matrix Metalloproteinase-8 Chairside Mouthrinse Test in Adolescents. Journal of Periodontology. 2016; 87(1), p. 36-40.

17. SLOWEY PD. Saliva collection devices and diagnostic platforms. In Advances in Salivary Diagnostics. 2015; p. 3361.

18. WANG Y. Evaluation of saliva and plasma cytokine biomarkers in patients with oral squamous cell carcinoma. International Journal of Oral and Maxillofacial Surgery. 2017. 